\title{
Analysis of Inductance Gradient and Current Density Distribution Over Different Cross-section of Rails
}

\author{
M. N. Saravana Kumar ${ }^{1}$, R. Murugna ${ }^{2}$ \\ ${ }^{1}$ Departement of Electrical and Electronics Engineering, St. Peters University, Chennai, TN, India \\ ${ }^{2}$ Departement of Electrical and Electronics Engineering, St. Joseph's Institute of Technology, Chennai, TN, India
}

\begin{tabular}{l} 
Article Info \\
\hline Article history: \\
Received Oct 2, 2017 \\
Revised Dec 26, 2017 \\
Accepted Jan 8, 2018 \\
\hline
\end{tabular}

Keyword:

Current density

FEA

Inductance gradient

Magnetic flux density

Repulsive force

\begin{abstract}
In a rail gun system the armature accelerated due to the Lorentz force caused by the current which is diffused in to the rails. The entire system depends on the inductance gradient of the rail which is directly connected to the accelerating performance and efficiency of railgun. Hence, the exact analysis of inductance gradient is extremely significant for the railgun design. Since short duration of current pulse is applied to the rails determination of inductance gradient is very difficult. The inductance gradient varies with the geometric dimensions of the rails and armature. And it can be calculated with analytical method and numerical methods. In this paper inductance gradient of the rail has been computed and compared with the different rail crosssectional models using Ansoft Maxwell Eddy current solver uses finite element technique to calculate the field distribution in a space. The current density, magnetic flux density, repulsive force acting on the rails also computed to analyze the performance of rail gun.
\end{abstract}

Copyright $@ 2018$ Institute of Advanced Engineering and Science. All rights reserved.

\section{Corresponding Author:}

M. N. Saravana Kumar, Departement of Electrical and Electronics Engineering,

St. Peters University,

Chennai, Tamil Nadu, India.

Email: saranviharece2009@gmail.com

\section{INTRODUCTION}

Railgun works under the principle of Lorentz force, when the current passes through one rail and it will pass to the armature (i.e., projectile) and then it will be returned back through the other rail by generating the magnetic fluxes over the rail which causes electromagnetic effect in the railgun. Because of this effect, the Lorentz force principle has been executed results in accelerating the armature, which has been shown in Figure 1.

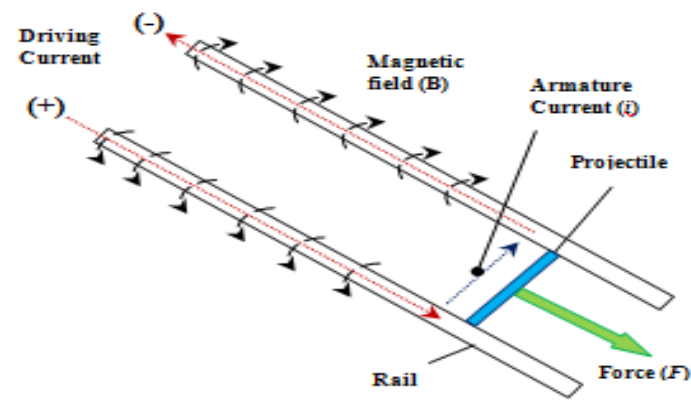

Figure 1. A Simple Railgun representation 
Inductance gradient, magnetic flux density, current distribution over the rails, repulsive force acting on the rails and temperature are the major key parameters of the railgun. Projectile force and the gradient of inductance are directly proportional as $F=\frac{1}{2} L^{\prime} I^{2}$. Based on this equation; the Projectile can achieve hyper velocity on considering the input current and the gradient inductance (L') [1]. For the several decades the researchers were focused on computing Inductance gradient (L') by varying the width (w), height (h) and separation (s) between the two rails. Different cross-section of rails has been considered for finding the inductance gradient (L') by 'Eddy Current' solver for various (s), (w), (h) [2]. The rail gun is supplied with large current as a result, thermal energy is generated which changes the electrical and thermal properties of the rail materials. Hence, in order to gain a quantitative understanding of these parameters, it is desirable to calculate them in advance [3]. In general, these values are affected by number of parameters such as velocity of the moving armature and rail geometry, rail dimensions, armature and rail materials [4-7]. Maxwell's equation was one of the elegant ways for describing the fundamentals of electric and magnetic factors of the system. A small modification in the electromagnetic theory leads to modify the lorrentz force law and Maxwell's equations [8].

Comparision has been done on rectangular, convex and concave rail cross sections on changing the geometric dimension. When the area of cross section is decreased the current density distribution may be uniform which tends to high inductance gradient [9], [10]. Huerta et al. [11] has calculated the inductance gradient of the rails by using conformal mapping method. Ellies et al. [12] have studied the influence of bore and rail geometry by using 2-D, A.C finite element method with high frequency limit. Patch et al. [13] has analyzed the rail barrel design using A.C analysis. Armature velocity can be calculated by finding the accelratinf force at the time of launch and displacement of the armature. Force-displacement sensors were used to find the accelerating force and the displacement [15], [16]. From the above literature review, it has been observed that for the past several years, various numerical and analytical methods were developed to compute the rail gun key parameters. These parameters can be calculated either by transient analysis or A.C method in the high frequency limit. In all these cases, the current is distributed over the surface of the conductor. This is a good approximation for rail guns to choose good conductor. The objective of this work is to determine the gradient of inductance (L') over the different cross section of the rails for various height (h), width (w) and separation (s) between the two rails by means of '2-D Eddy Current' solver using Ansoft Maxwell, which is popular for finite element analysis.

\section{MAJOR KEY PARAMETER ANALYSES ON DIFFERENT CROSS SECTION OF RAILS}

Simulation setup have been made based on the basic combination of symmetric and asymmetric geometric dimension parameters of the rails are set as $\mathrm{w}=2 \mathrm{~cm}, \mathrm{~s}=2 \mathrm{~cm}, \mathrm{~h}=2 \mathrm{~cm}$, radius $=0.5 \mathrm{~cm}$ (for concave and convex rail). Here, the analyses have been made with the same rail (copper - conductivity of $5.8 \times 10^{\wedge} 7$ and relative permeability of 0.999991) material, fixed solver (Eddy Current) and uniform current input (300kA) with Adaptive frequency of $2 \mathrm{kHz}$, for various cross sections of the rails with various dimensions using finite element analysis. Figure 2 shows the different cross-section of the rail in the railgun system for analyzing the inductance gradient (L') and Current Distribution.

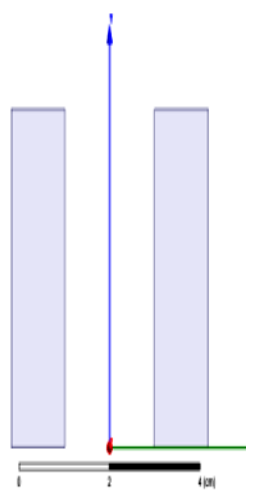

(a)

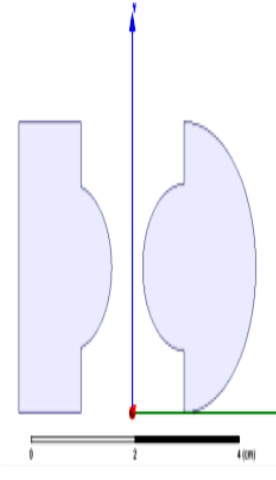

(b)

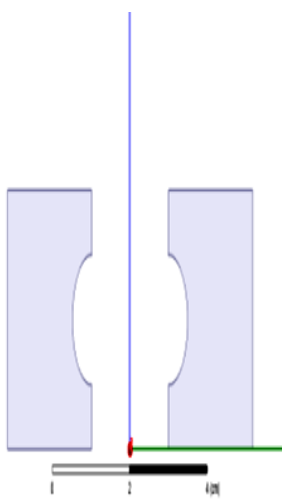

(c)

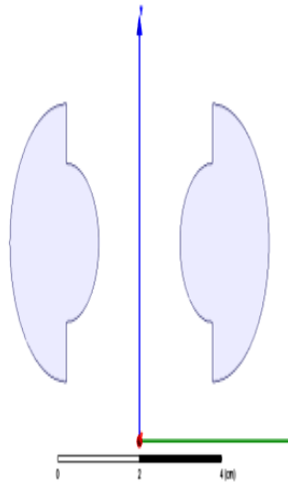

(d)

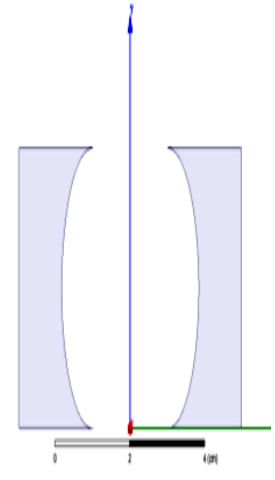

(e)

Figure 2. Different rail cross-sections in the railgun system, (a) Rectangular, (b) Rectangular-Circular Convex, (c) Rectangular Concave, (d) Rectangular Semi-Concave, (e) Circular Convex 


\section{RESULTS AND DISCUSSIONS}

\subsection{Comparision of Rail Design Parameter with Different Rail Shapes}

\subsubsection{Inductance Gradient for Different Rail shapes}

Inductance gradient plays an vital role for the launching system. When the input supply current is high the current distribution won't be uniformly distributed over the rail and armature. On concentrating on achieving high L' value the distribution of current may be made uniform. Inductance gradients (L') of the rails were computed for various rail shapes shown in Figure 2. It has been analyzed by changing the single parameter, i.e., only varying the height (h) and making the other dimensions as constant. The corresponding results of the calculated inductance gradient (L') are tabulated in Table 1.

Table 1. Comparison of L' with Different Rail shapes

\begin{tabular}{|c|c|c|c|c|}
\hline \multirow{2}{*}{ Rail Model } & \multicolumn{3}{|c|}{ Inductance Gradient( $\left.\mathrm{L}^{\prime}\right)$ in $(\mu \mathrm{H})$} & \multirow{2}{*}{2} \\
\hline & \multicolumn{3}{|c|}{ Height $(\mathrm{h})$ of the Rail in $(\mathrm{cm})(\mathrm{w}=\mathrm{s}=2 \mathrm{~cm}$, radius $=0.5 \mathrm{~cm})$} & \\
\hline Rectangular & 0.5412 & 0.5619 & 0.6227 & 0.6512 \\
\hline Rectangular Semi-Concave & 0.4696 & 0.5725 & 0.6316 & 0.6585 \\
\hline Circular Convex & 0.6706 & 0.7032 & 0.7196 & 0.7368 \\
\hline
\end{tabular}

As seen from the Table 1, it has been observed that the inductance gradients increase on varying the height for different cross section of the rails. As compared to other rail shapes, circular convex shaped rail cross-section shows high value of L' shown in Figure 3.

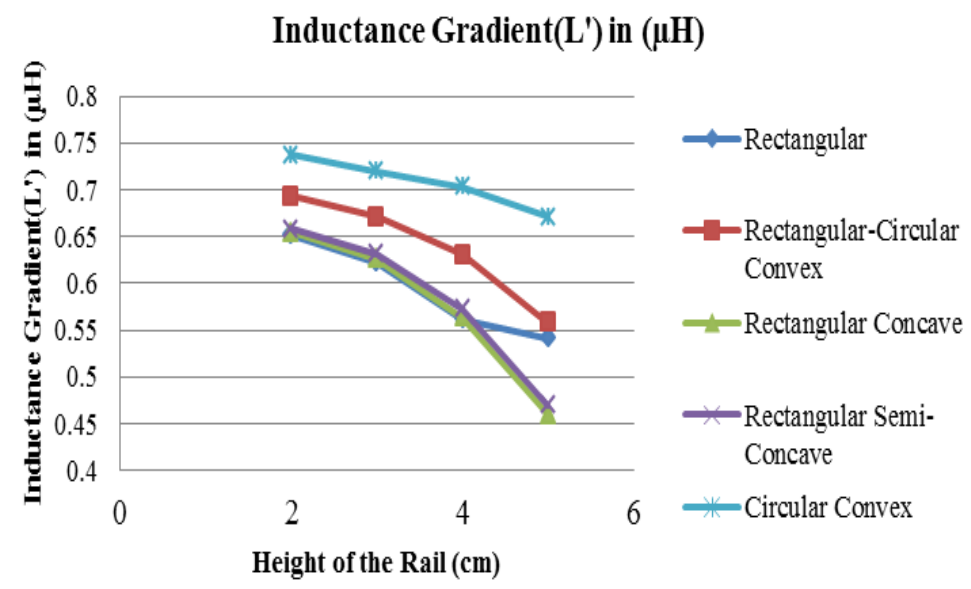

Figure 3. Inductance Gradient for Different Rail shapes

\subsection{Current Density for Different Rail shapes}

During the electromagnetic launch, the current distribution is not uniform over the rail due to high input impedance. This can be minimized by choosing the proper material and by selecting the appropriate rail shape [14]. Here, the Current density (J) of the rails was computed for various rail shapes shown in Figure 2 and the obtained current density field plots were displayed in Figure 4. It has been analyzed by only varying the height (h) and making the other dimensions as constant. The corresponding results are tabulated in Table 2 .

The current density distribution for different rail cross-section shown in Figure 2 had been developed and displayed graphically in Figure 5. In this analysis, the circular convex shaped rail crosssection shows uniform variation on varying the rail height comparing to other rail shapes. 
Table 2. Comparison of J with Different Rail Shapes

Current Density $(\mathrm{J}) \times 10^{9}$ in $\left(\mathrm{A} / \mathrm{m}^{2}\right)$

\begin{tabular}{lccc} 
& \multicolumn{3}{c}{ Height $(\mathrm{h})$ of the Rail in $(\mathrm{cm})(\mathrm{w}=\mathrm{s}=2 \mathrm{~cm}$, radius $=0.5 \mathrm{~cm})$} \\
& 2 & 3 & 4 \\
\hline Rectangular & 4.8923 & 4.8735 & 4.8515 \\
Rectangular-Circular Convex & 6.0003 & 5.3693 & 4.7263 \\
Rectangular Concave & 5.8706 & 5.0167 & 4.3716 \\
Rectangular Semi-Concave & 7.2428 & 7.1253 & 6.189 \\
Circular Convex & 7.0531 & 5.7853 & 4.926 \\
\hline
\end{tabular}

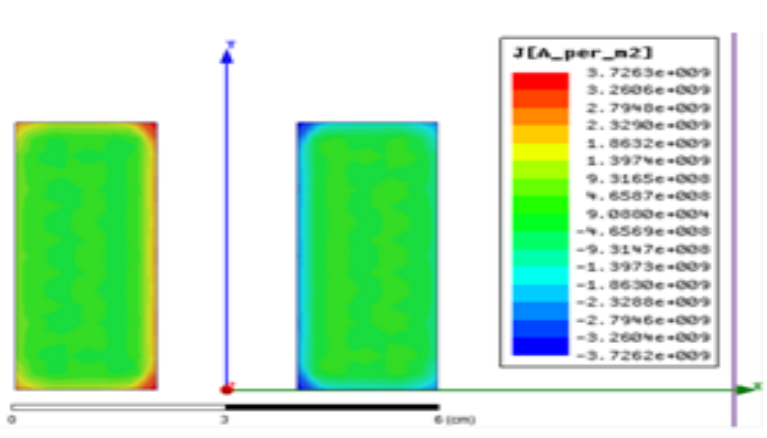

(a) Rectangular

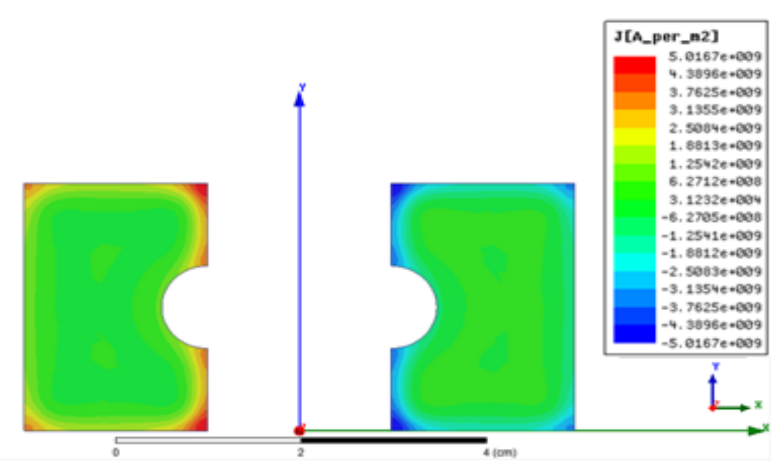

(c) Rectangular concave

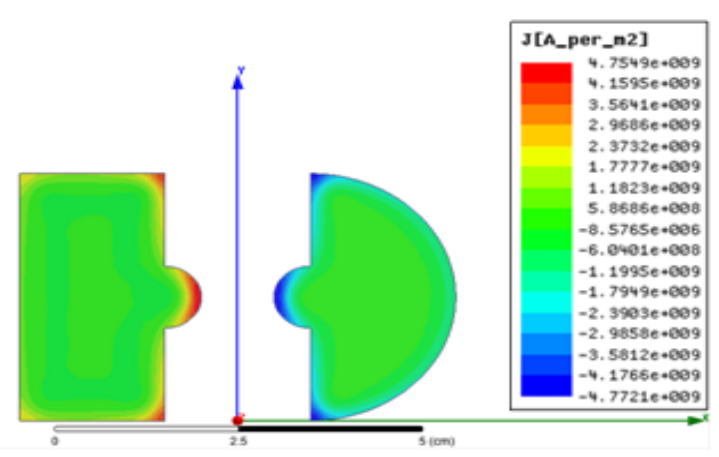

(b) Rectangular-Circular convex

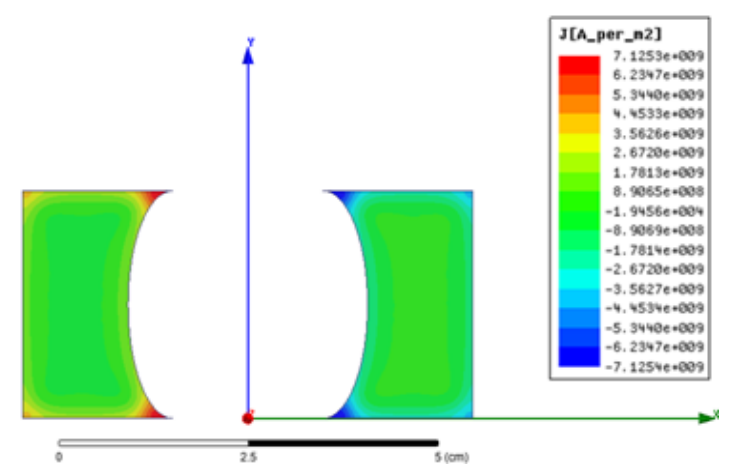

(d) Rectangular Semi-concave

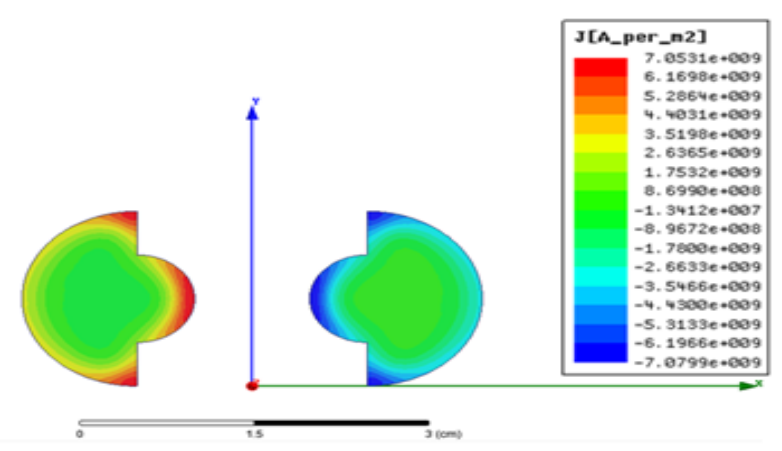

(e) Circular Convex

Figure 4. Current Density over the different rail shapes 


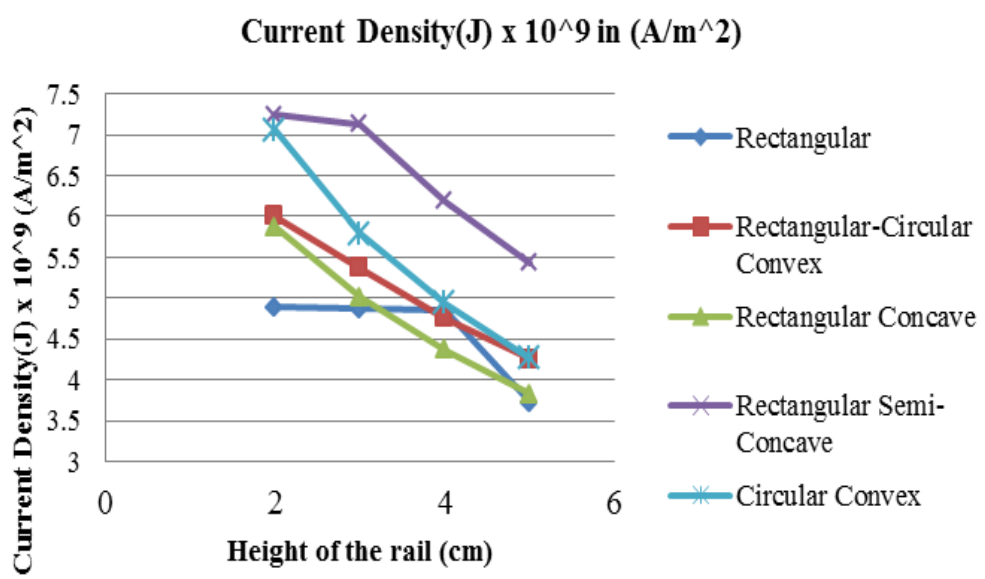

Figure 5. Current Density for different Rail model

\subsection{Analysis of Different Shaped Rail Cross-sectional Railgun by considering the Cross-sectional} Surface Area to be Constant

In the above section the analyses has been done by varying the rail dimensions without considering the area as constant. Here in this section the area of the rail is made constant as $4 \mathrm{~cm}^{2}$ and the key parameters were compared with different rail shapes shown in Table 3.

Table 3. Tabulation on various parameters of rail with constant area

\begin{tabular}{|c|c|c|c|c|}
\hline Different Rail Shape & $\begin{array}{c}\mathrm{J} \\
\mathrm{X} 10^{9} \\
\left(\mathrm{~A} / \mathrm{m}^{2}\right)\end{array}$ & $\begin{array}{c}L^{\prime} \\
(\mu \mathrm{H})\end{array}$ & $\begin{array}{c}F_{1} \\
-(k N)\end{array}$ & $\begin{array}{c}\mathrm{F}_{2} \\
(\mathrm{kN})\end{array}$ \\
\hline Rectangular Rail & 5.36 & 0.66 & 158.09 & 158.07 \\
\hline Rectangular-Circular Convex Rail & 6.20 & 0.66 & 314.75 & 315.64 \\
\hline Rectangular Concave Rail & 5.64 & 0.43 & 82.87 & 82.91 \\
\hline Rectangular Semi-Concave Rail & 8.09 & 0.57 & 90.11 & 90.12 \\
\hline Circular Convex Rail & 7.24 & 0.69 & 409.37 & 409.36 \\
\hline
\end{tabular}

The current density field plot for different rail models shown in Figure 6, by considering the rail area to be constant as $4 \mathrm{~cm}^{2}$. 


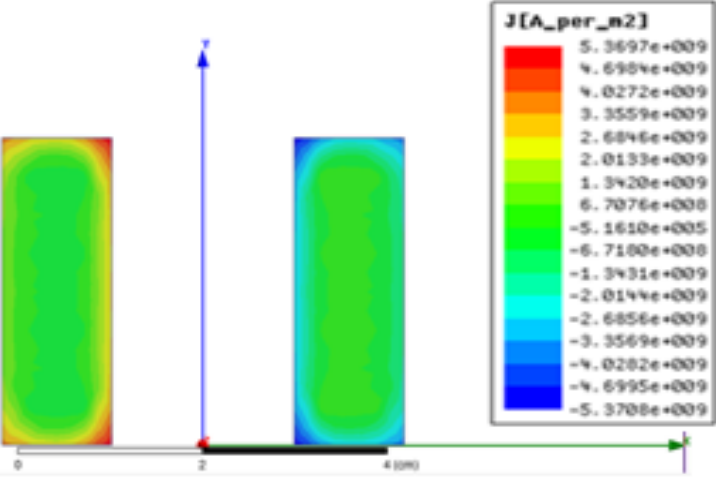

(a) Rectangular

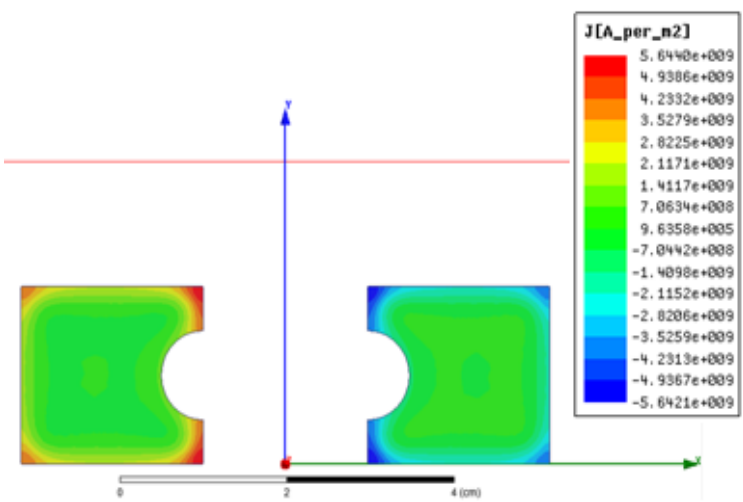

(c) Rectangular concave

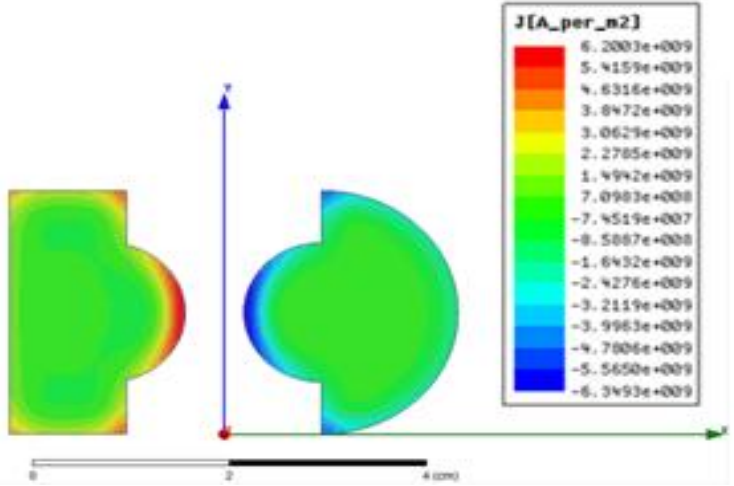

(b) Rectangular-Circular convex

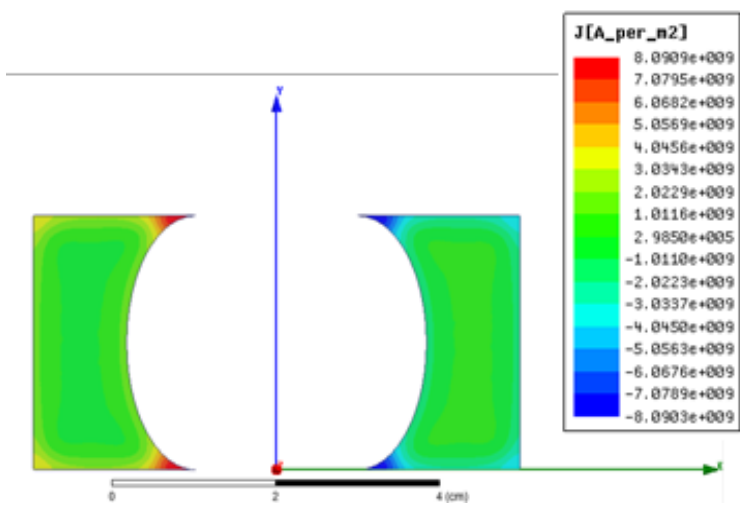

(d) Rectangular Semi-concave

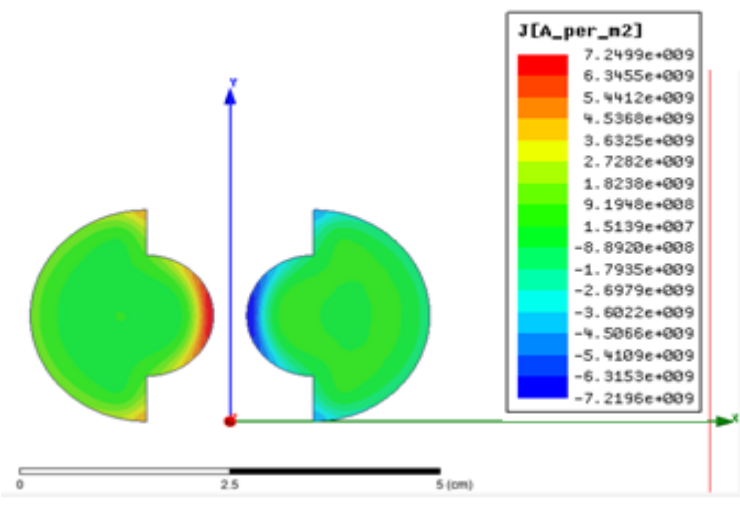

(e) Circular Convex

Figure 6. Current Density over the different rail cross-section by considering the cross-sectional area as constant

\section{CONCLUSION}

This paper investigates the inductance gradient (L') and Current density (J) on varying the geometric dimensions of the different rail cross-sections. In this paper it has been analysed in two ways.

a. The height of the rail cross-section has been adjusted, without considering the cross-sectional area of the rail as constant. It has been seen that circular convex rail cross-section shows high inductance gradient value which tends to uniform current density distribution over the rail that has been tabulated in the comparison Table 1 and Table 2 . 
b. The height of the rail cross-section has been adjusted, by considering the rail with constant area of $4 \mathrm{~cm}^{2}$. Accordingly, the simulation results were tabulated in the comparison Table 3 , here too the convex shaped rail shows more efficient than other rail models.

On adjusting the dimension of the rail and making the area has to be constant the Circular Convex Rail cross-section shows uniform current distribution over the rail and with high value of inductance gradient. So that, on by choosing a proper rail material, the Circular Convex Rail shows a better efficient for the EM launch.

\section{REFERENCES}

[1] Keshtkar A. (2005), "Effect of rail dimension on current distribution and inductance gradient", IEEE Trans. Magn., vol. 41, No. 1, pp. 383-386.

[2] Zhou Y., YAN P., Yuan W.Q, Wang J., Li M.T. (2009) "Current Distribution And Inductance Gradient Calculation At Different Rail Geometric Parameters”, IEEE, pp. 1290-1293

[3] Jerry F. Kerrisk (1984), "Electrical and Thermal Modeling of Railguns", IEEE Trans. Magn., Vol.Mag-20, No. 2, pp. 393-402.

[4] Murugan.R and Udhayakumar.K (2005), "Effect of Rail Dimensions on Rail gun Design Parameters", IEEE Indicon 2005 Conference, Chennai, India, pp. 623-625.

[5] Stephan Hundertmark, Markus Schneide and Gregory Vincent (2013), "Payload Acceleration Using a 10-MJ DES Railgun”, IEEE Trans.on Plasma Science, Vol.41, No.5, pp. 1455-1459.

[6] Barbara Wild, Christian Schuppler, Farid Alouahabi, Markus Schneide and Ryan Hoffman (2015), "The Influence of the Rail Material on the Multishot Performance of the Rapid Fire Railgun”, IEEE Trans.on Plasma Science, Vol.43, No.6, pp. 2095-2099.

[7] Mohammad Sajjad Bayati and Asghar Keshtkar (2015), "Novel Study of the Rail's Geometry in the Electromagnetic Launcher”, IEEE Trans.on Plasma Scienc., Vol.43, No. 5, pp. 1652-1656.

[8] Asif Ali Laghari (2014), "Interpretaion of Modified Electromagnetic theory and Maxwell's equations on Basic of Charge variation”, International Journal of Electrical and Computer Engineering, Vol. 4, No.2, pp. 231-236.

[9] Lonwen Jin, Bin Lei, Qian zhang and Rengui Zhu (2015), "Electromechnaical Performance of Rails with different cross-sectional shapes in Railgun”, IEEE Trans.on Plasma Science., Vol.43, No.5, pp. 1220-1224.

[10] Mohammad sajjad Bayati and Asghar Keshtkar (2015), "Novel Study of Rail's Geometry in the Electromagnetic Launcher", IEEE Trans.on Plasma Science., Vol.43, No. 5, pp. 1652-1656.

[11] Huerta M. A. and Nearing J. C. (1991), "Conformal Mapping Calculation Of Railgun Skin Inductance", IEEE Trans. Magn., vol. 27, No. 1, pp. 112-115.

[12] Ellis R. L., Poynor J. C., Mc Glasson B. T. and Smith A. N ( 2005), "Influence of bore and rail geometry on an electromagnetic naval railgun system", IEEE Trans. Magn., Vol. 41, No. 1, pp. 182-187.

[13] Patch L., Comstock J. M., Thio Y. C. and Young F. J. (1984), "Railgun Barrel Design and Analysis", IEEE Trans. Magn., Vol. Mag-20, No.2, pp. 360-363.

[14] Jerry F. Kerrisk (1984), "Electrical and Thermal Modeling of Railguns", IEEE Trans. Magn., Vol.Mag-20, No.2, pp. 393-402.

[15] Amine Benabdellah, Zakarya Abbassi and Abdelrhani Nakheli (2016), "New Electromagnetic Force-Displacement Sensor", Bulletin of Electrical Engineering and Informatics, Vol. 5, No. 3, pp. 334-339.

[16] Amine Benabdellah, Zakarya Abbassi and Abdelrhani Nakheli (2016), "New Electromagnetic Force-Displacement Sensor", Bulletin of Electrical Engineering and Informatics, Vol. 5, No. 4, pp. 451-455.

\section{BIOGRAPHIES OF AUTHORS}

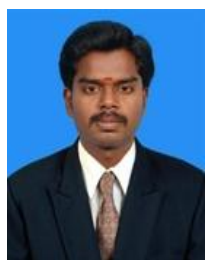

M. N. Saravana Kumar has received his Bachelor's Degree in Electronics and Communication Engineering in Bhajarang Engineering College, Chennai, Tamil Nadu, India in the year 2009, then he received his Master of Engineering Degree in Power Electronics and Drives from Rajalakshmi Engineering College, Chennai in the year 2013. At present he is pursuing Ph.D. in Electrical and Electronics Engineering in St. Peter's University, chennai. Tamil Nadu, India. His Areas of interests is Power Electronics, Electro-magnetic Field.

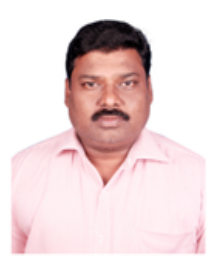

R. Murugan has received bachelor's Degree in Electrical and Electronics Engineering from University of Madras, Tamilnadu, India in April 1996. Then, he received his Master's Degree High Voltage Engineering from College of Engineering, Anna University, Guindy, Chennai, Tamil Nadu, India in February 1999. Then Ph.D degree in Electrical and Electronics Engineering department from Anna University, Chennai, Tamil Nadu, India in 2011. His main areas of interest are Electromagnetic field and High Voltage Engineering. 